\title{
Perancangan Aplikasi Rekomendasi Pemilihan Lokasi Rumah dengan Memanfaatkan Fuzzy Database Metode Tahani
}

\author{
Sathya Adi Dharma \\ Program Studi Teknik Informatika \\ Fakultas Teknologi Informasi \\ Institut Informatika Indonesia \\ rlsvv@yahoo.com
}

\author{
Timothy John Pattiasina \\ Program Studi Manajemen \\ Informatika \\ Fakultas Teknologi Informasi \\ Institut Informatika Indonesia \\ temmy@ikado.ac.id
}

\author{
Edwin Meinardi Trianto \\ Program Studi Teknik Informatika \\ Fakultas Teknologi Informasi \\ Institut Informatika Indonesia \\ edwin@ikado.ac.id
}

\begin{abstract}
Abstrak - Pemilihan lokasi rumah memerlukan beberapa kriteria yang cocok dengan kebutuhan konsumen. Biasanya konsumen mencari informasi perumahan lewat brosur-brosur rumah atau mengunjungi pameran perumahan. Hal itu dirasa kurang efektif karena memerlukan waktu yang lama. Salah satu cara dalam menentukan lokasi rumah adalah dengan menggunakan fuzzy database dengan model Tahani. Fuzzy database model Tahani merupakan salah satu metode yang dapat digunakan pada proses pengambilan keputusan. Dalam penelitian ini, aplikasi fuzzy database model Tahani dibangun untuk membantu pihak agen perumahan dalam memberikan rekomendasi rumah kepada konsumen, sehingga konsumen dapat memilih rumah sesuai dengan kriteria yang dipilihnya dengan lebih cepat dan mudah. Pada aplikasi yang telah dibangun, hasil rekomendasi rumah didasarkan pada nilai derajat keanggotaan dan fire strength (nilai kebenaran) dari proses perhitungan di dalam aplikasi tersebut.

Kata Kunci - Fuzzy Database model Tahani, Fire Strength, Rekomendasi
\end{abstract}

\section{PENDAHULUAN}

Basis Data (Database) merupakan kumpulan beberapa data yang saling berhubungan dan terkait satu dengan yang lainnya dan dapat di manipulasi. Sedangkan sistem basis data merupakan suatu aplikasi yang mengintegrasikan kumpulan data yang saling berhubungan satu dengan yang lainnya dan membuatnya tersedia untuk beberapa aplikasi dalam suatu organisasi.

Sebagai salah satu contoh adalah ketika hendak menentukan pemilihan lokasi rumah yang akan dibeli dengan perbandingan rekomendasi yang ada. Pada proses pemberian rekomendasi lokasi rumah, tentunya ada kriteriakriteria yang ditentukan oleh konsumen sehingga nantinya mendapatkan suatu hasil rekomendasi lokasi melalui sistem sesuai dengan keinginannya. Data-data yang akan dimasukkan kedalam database adalah lokasi rumah dan kriteria-kriteria pemilihan lokasi rumah. Dasar penilaian terhadap rekomendasi lokasi rumah yang diberikan kepada konsumen tidak hanya dinilai dari indeks harga saja, akan tetapi juga harus memperhatikan kriteria-kriteria lainnya sebagai penentu lokasi rumah yang dijual, seperti apakah dekat dengan minimarket, sarana pendidikan, fasilitas umum, dan sarana kesehatan, serta fasilitas pendukung yang dimiliki.

Seiring dengan perkembangan kemajuan teknologi dan informasi maka munculah beberapa lokasi rumah yang memiliki fasilitas yang diperlukan oleh konsumen, dan jumlahnya tidak sedikit maka disini dibutuhkan kejelian dari konsumen dalam memilih lokasi rumah yang sesuai dengan selera masing-masing. Tetapi proses ini sangat menyita waktu bagi konsumen bahkan dapat membingungkan konsumen itu sendiri dalam melakukan pemilihan. Dalam hal ini bisa menimbulkan ketidakpuasan dari konsumen setelah membeli rumah, karena kurangnya informasi.

Berdasarkan permasalahan tersebut, maka perlu dirancang sebuah aplikasi yang mampu menganalisa serta merekomendasikan lokasi rumah yang sesuai dengan kriteria yang diinginkan konsumen. Agar aplikasi ini dapat berjalan dengan baik, maka perlu didefinisikan secara baku tentang kriteria-kriteria untuk mendapatkan rekomendasi lokasi rumah yang diinginkan oleh konsumen. Berdasarkan kriteria-kriteria inilah nantinya aplikasi akan menganalisa lokasi rumah yang ada. Metode yang digunakan untuk aplikasi ini adalah dengan memanfaatkan fuzzy database metode tahani.

\section{METODOLOGI PENELITIAN}

Telah diketahui pada pendahuluan bahwa terdapat beberapa hal yang berperan penting dalam perancangan aplikasi rekomendasi lokasi rumah dengan memanfaatkan fuzzy database metode tahani. Hal-hal tersebut akan dijabarkan pada sub-bab dibawah ini:

\section{A. Metode Fuzzy}

Logika fuzzy pertama kali ditemukan oleh profesor Lotfi A. Zadeh, dari Universitas California, pada bulan Juni 1965. Logika fuzzy merupakan generalisasi dari logika klasik yang hanya memiliki dua nilai keanggotaan, yaitu 0 dan $1^{[1]}$. 
Dalam logika fuzzy, nilai kebenaran suatu pernyataan berkisar dari sepenuhnya benar, sampai dengan sepenuhnya salah. Dengan teori himpunan fuzzy, suatu objek dapat menjadi anggota dari banyak himpunan dengan derajat keanggotaan yang berbeda dalam masing-masing himpunan. Konsep ini berbeda dengan himpunan klasik (crisp). Teori himpunan klasik tergantung pada logika dua nilai (two valued logic) untuk menentukan apakah sebuah objek merupakan suatu anggota himpunan atau bukan.

\section{- Himpunan Fuzzy}

Himpunan fuzzy memiliki 2 atribut, yaitu :

1. Linguistik, yaitu penamaan suatu grup yang mewakili suatu keadaan atau kondisi tertentu dengan menggunakan bahasa alami, seperti : Muda, Tua, Parobaya.

2. Numeris, yaitu suatu nilai (angka) yang menunjukkan ukuran dari suatu variabel seperti : 40, 25, 50.

Ada beberapa hal yang perlu diketahui dalam memahami sistem fuzzy, yaitu:

1. Variabel Fuzzy

Variabel fuzzy merupakan variabel yang akan dibahas dalam suatu sistem fuzzy.

2. Himpunan Fuzzy

Himpunan fuzzy merupakan suatu grup yang mewakili suatu kondisi atau keadaan tertentu dalam suatu variabel fuzzy.

3. Semesta Pembicaraan

Semesta pembicaraan adalah keseluruhan nilai yang diperbolehkan untuk dioperasikan dalam suatu variabel fuzzy. Semesta pembicaraan merupakan himpunan bilangan real yang senantiasa naik (bertambah) secara monoton dari kiri ke kanan. Nilai semesta pembicaraan dapat berupa bilangan positif maupun negatif. Seharusnya nilai semesta pembicaraan ini tidak dibatasi batas atasnya.

\section{- Domain}

Domain himpunan fuzzy adalah keseluruhan nilai yang diijinkan dalam semesta pembicaraan dan boleh dioperasikan dalam suatu himpunan fuzzy. Seperti halnya semesta pembicaraan, domain merupakan himpunan bilangan real yang senantiasa naik (bertambah) secara monoton dari kiri ke kanan. Nilai domain dapat berupa bilangan positif maupum negatif.

\section{- Fungsi Keanggotaan}

Fungsi keanggotaan adalah grafik yang mewakili besar dari derajat keanggotaan masing-masing variabel input yang berada dalam interval antara 0 dan 1 . Derajat keanggotaan sebuah variabel $x$ dilambangkan dengan simbol $\mu(x)$. Rule menggunakan nilai keanggotaan sebagai faktor bobot untuk menentukan pengaruhnya pada saat melakukan inferensi untuk menarik kesimpulan. Ada beberapa fungsi yang bisa digunakan antara lain:

- Representasi Linear Naik

Kenaikan himpunan dimulai pada nilai domain yang memiliki derajat keanggotaan nol (0) bergerak ke kanan menuju ke nilai domain yang memiliki derajat keanggotaan lebih tinggi.

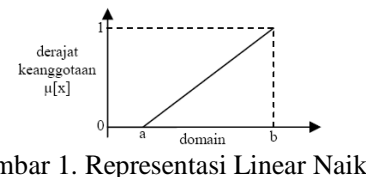

- Representasi Linear Turun

Representasi linear turun merupaka kebalikan dari linear naik. Garis lurus dimulai dari nilai domain dengan derajat keanggotaan tertinggi pada sisi kiri, kemudian bergerak menurun ke nilai domain yang memiliki derajat keanggotaan lebih rendah.

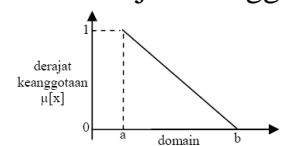

Gambar 2. Representasi Linear Turun

- Representasi Kurva Segitiga

Kurva segitiga pada dasarnya merupakan gabungan antara 2 garis (linear).

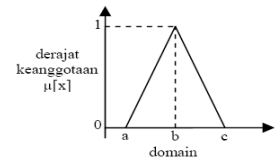

Gambar 3. Representasi Kurva Segitiga

- Representasi Kurva Trapesium

Kurva trapesium pada dasarnya seperti bentuk segitiga, hanya saja ada beberapa titik yang memiliki nilai keanggotaan 1 .

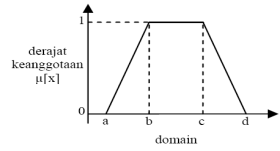

Gambar 4. Representasi Kurva Trapesium

- Representasi Kurva Bentuk Bahu

Daerah yang terletak di tengah-tengah suatu variabel yang dipresentasikan dalam bentuk segitiga, pada sisi kanan dan kirinya akan naik dan turun. (misalkan : DINGIN bergerak ke SEJUK bergerak ke HANGAT dan bergerak ke PANAS). Tetapi terkadang salah satu sisi dari variabel tersebut tidak mengalami perubahan. Sebagai contoh, apabila telah mencapai kondisi PANAS, kenaikan temperatur akan tetap berada pada kondisi PANAS. Himpunan fuzzy 'bahu', bukan segitiga, digunakan untuk mengakhiri variabel suatu daerah fuzzy. Bahu kiri bergerak dari benar ke salah, sebaliknya bahu kanan bergerak dari salah ke benar.

Gambar berikut menunjukkan variabel temperatur dengan daerah bahunya.

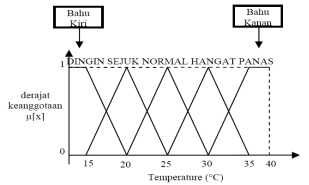

Gambar 5. Representasi Kurva Bentuk Bahu 
- Representasi kurva-S Pertumbuhan Kurva pertumbuhan dan penyusutan merupakan kurva-I Kurva-S untuk pertumbuhan akan bergerak dari sisi paling kiri (nilai keanggotaan = 0 ) ke sisi paling kanan (nilai keanggotaan $=1$ ).

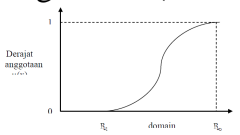

Gambar 6. Representasi Kurva-S Pertumbuhan

- Representasi kurva-S Peyusutan

Kurva-S untuk penyusutan akan bergerak dari sisi paling kanan (nilai keanggotaan $=1$ ) ke sisi paling kiri (nilai keanggotaan $=0$ )

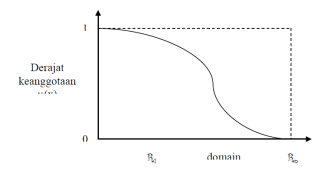

Gambar 7. Representasi Kurva-S Penyusutan

\section{B. Fuzzy Database Metode Tahani}

Fuzziness dapat didefinisikan sebagai logika kabur berkenaan dengan semantik dari suatu kejadian, fenomena atau pernyataan itu sendiri. Seringkali ditemui dalam pernyataan yang dibuat oleh seseorang, evaluasi dan suatu pengambilan keputusan. Sebagai contoh: mengkategorikan usia karyawan di atas ke dalam himpunan (MUDA, PAROBAYA, dan TUA). Dengan informasi yang bersifat ambigu tersebut, maka digunakan fuzzy database. Salah satu diantaranya adalah Model Tahani. Fuzzy database metode Tahani menggunakan teori himpunan fuzzy untuk mendapatkan informasi query-nya.

Metode fuzzy database model Tahani tersusun atas tahapan, yaitu:

- Tahap 1. Menggambarkan Fungsi Keanggotaan

Fungsi keanggotaan (membership function) adalah suatu kurva yang menunjukkan pemetakan titik-titik input data kedalam nilai keanggotaannya (sering juga disebut dengan derajat keanggotaan) yang memiliki internal antara 0 sampai 1, salah satu cara yang dapat digunakan untuk mendapatkan nilai keanggotaan adalah dengan melalui pendekatan fungsi. Beberapa fungsi yang dapat digunakan yaitu:

a. Representasi linear

b. Representasi Kurva Segitiga

c. Representasi Kurva Trapesium

Masing-masing fungsi tersebut, akan menghasilkan nilai antara " 0 " dan " 1 " dengan cara yang berbeda, sesuai dengan jenis representasi yang digunakan. Apabila $\mu S$ adalah fungsi keanggotaan suatu elemen pada himpunan $S$ maka untuk suatu elemen $X$ dapat dinyatakan $\mu S(X)$ yang bernilai antara "0" dan " 1 " sehingga ada tiga kemungkinan:

$\mu \mathrm{S}(\mathrm{X})=1 \rightarrow \mathrm{X}$ mutlak anggota $\mathrm{S}$.

$\mu \mathrm{S}(\mathrm{X})=0 \rightarrow \mathrm{X}$ mutlak bukan anggota $\mathrm{S}$.

$\mu \mathrm{S}(\mathrm{X})<1 \rightarrow \mathrm{X}$ anggota $\mathrm{S}$ dengan derajat keanggotaan antara 0 dan 1.

- Tahap 2. Fuzzyfikasi
Fuzzyfikasi adalah fase pertama dari perhitungan fuzzy yaitu pengubahan nilai tegas ke nilai fuzzy. Prosesnya adalah sebagai berikut: suatu besaran analog dimasukkan sebagai input (crisp input), lalu input tersebut dimasukkan pada batas scope/dominan dari membership function. Membership function ini biasanya dinamakan membership function input. Output dari proses fuzzifikasi ini adalah sebuah nilai input fuzzy atau yang biasanya dinamakan fuzzy input.

- Tahap 3. Fuzzyfikasi Query

Fuzzyfikasi Query diasumsikan sebuah query konvensional (nonfuzzy) DBMS yang akan mencoba membuat dan menerapkan sebuah sistem dasar logika fuzzy query (fuzzy logic based querting system). Konsep dari sebuah relasi fuzzy dalam sebuah DBMS menggunakan derajat keanggotaan $\mu$ yang didefinisikan pada kumpulan domain $\mathrm{X}=(\mathrm{X} 1, \ldots, \mathrm{Xn})$, dan telah digenerate pada relasi luar oleh nilai tengah fuzzy. Sintaks query yang digunakan adalah sebagai berikut: "select from where"

- Tahap 4. Operator Dasar Zadeh untuk Operasi Himpunan Fuzzy

Pada seperti himpunan konfensional, ada beberapa operasi yang diidentifikasikan secara khusus untuk mengombinasikan dan memodifikasi himpunan fuzzy. Nilai keanggotaan sebagai dari 2 himpunan fuzzy dikenal dengan nama Fire Strength atau $\alpha$-predikat. Sangat mungkin digunakan operator dasar dalam proses query berupa operator $A N D$ dan $O R$. $\alpha$-predikat sebagai hasil operasi dengan operator $A N D$ diperoleh dengan mengambil nilai keanggotaan terkecil antar elemen pada himpunan-himpunan yang bersangkutan, dinotasikan : $\mu \mathrm{A} \cap \mathrm{B}=\min (\mu \mathrm{A}[\mathrm{x}], \mu \mathrm{B}[\mathrm{x}])$. Sedangkan untuk hasil operasi dengan operator $O R$ diperoleh dengan mengambil nilai keanggotaan terbesar antar elemen pada himpunan-himpunan yang bersangkutan, dinotasikan : $\mu \mathrm{AUB}=\max (\mu \mathrm{A}[\mathrm{x}], \mu \mathrm{B}[\mathrm{x}])$.

- Alternatif yang direkomendasikan adalah alternatif yang memiliki nilai Fire Strength atau tingkat kesesuaian dengan kriteria pilihan diatas angka 0 (nol) sampai dengan angka 1 (satu).

\section{HASIL DAN PEMBAHASAN}

Agar pengembangan aplikasi lebih maksimal, melakukan analisa terhadap aplikasi sangat penting, sehingga sistem yang akan dibangun memiliki acuan dan gambaran umum.

\section{A. Use Case Diagram}

Use Case Diagram pada aplikasi menjelaskan bagaimana jalannya sebuah aplikasi yang melibatkan lebih dari 1 aktor dalam kegiatannya. Untuk aplikasi yang akan dirancang, dibutuhkan 2 aktor utama yaitu admin dan konsumen. Setiap aktor memiliki aktivitas masing-masing. Berikut merupakan penjabaran dari interaksi apa saja yang terjadi dalam aplikasi yang akan dirancang. Untuk gambaran lebih jelas dapat dilihat pada gambar use case diagram berikut 


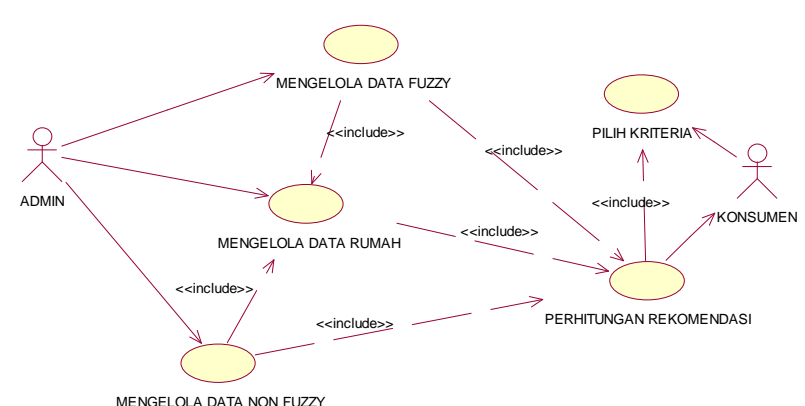

Gambar 8. Use Case Diagram

Dari gambar use case diagram, dapat dilihat bahwa admin bisa melakukan interaksi kedalam sistem, yaitu mengelola data rumah, mengelola data fuzzy, dan mengelola data non fuzzy. Sedangkan konsumen melakukan interaksi kedalam sistem, yaitu mengisi kriteria sesuai keinginan dan mendapatkan hasil rekomendasi.

\section{B. Activity Diagram}

Diagram ini mengandung aktivitas, pilihan tindakan, perulangan dan hasil dari aktivitas. Berikut adalah activityactivity diagram dari menu mengelola data rumah dan menu rekomendasi lokasi rumah. Berikut adalah activity diagram mengelola data rumah

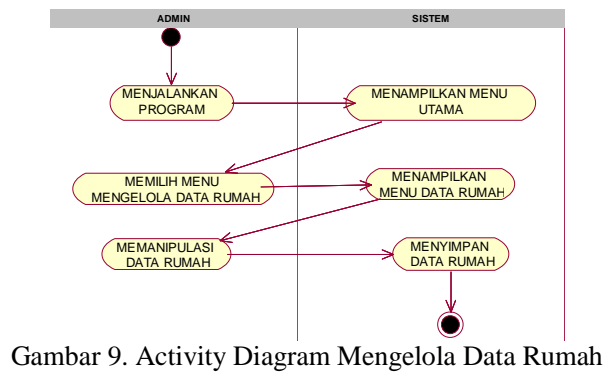

Sedangkan gambar activity diagram untuk menu rekomendasi lokasi rumah sebagai berikut

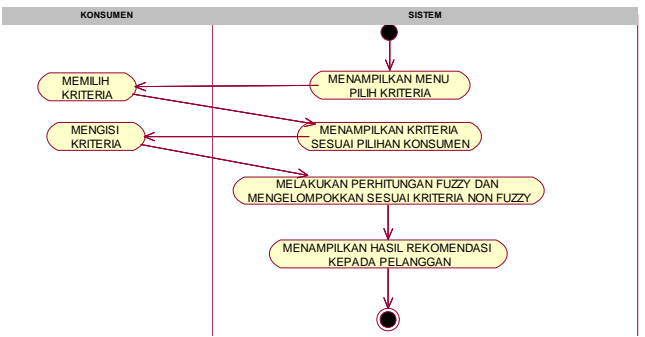

Gambar 10. Activity Diagram Rekomendasi Lokasi Rumah

\section{Pengelolaan Data}

Pengelolaan Data sangat dibutuhkan pada setiap sistem, tidak terkecuali bagi aplikasi ini. Pada aplikasi ini pengelolaan data menggunakan aplikasi database SQLServer. Gambar 11 adalah gambar Conceptual Data Model dari aplikasi ini.

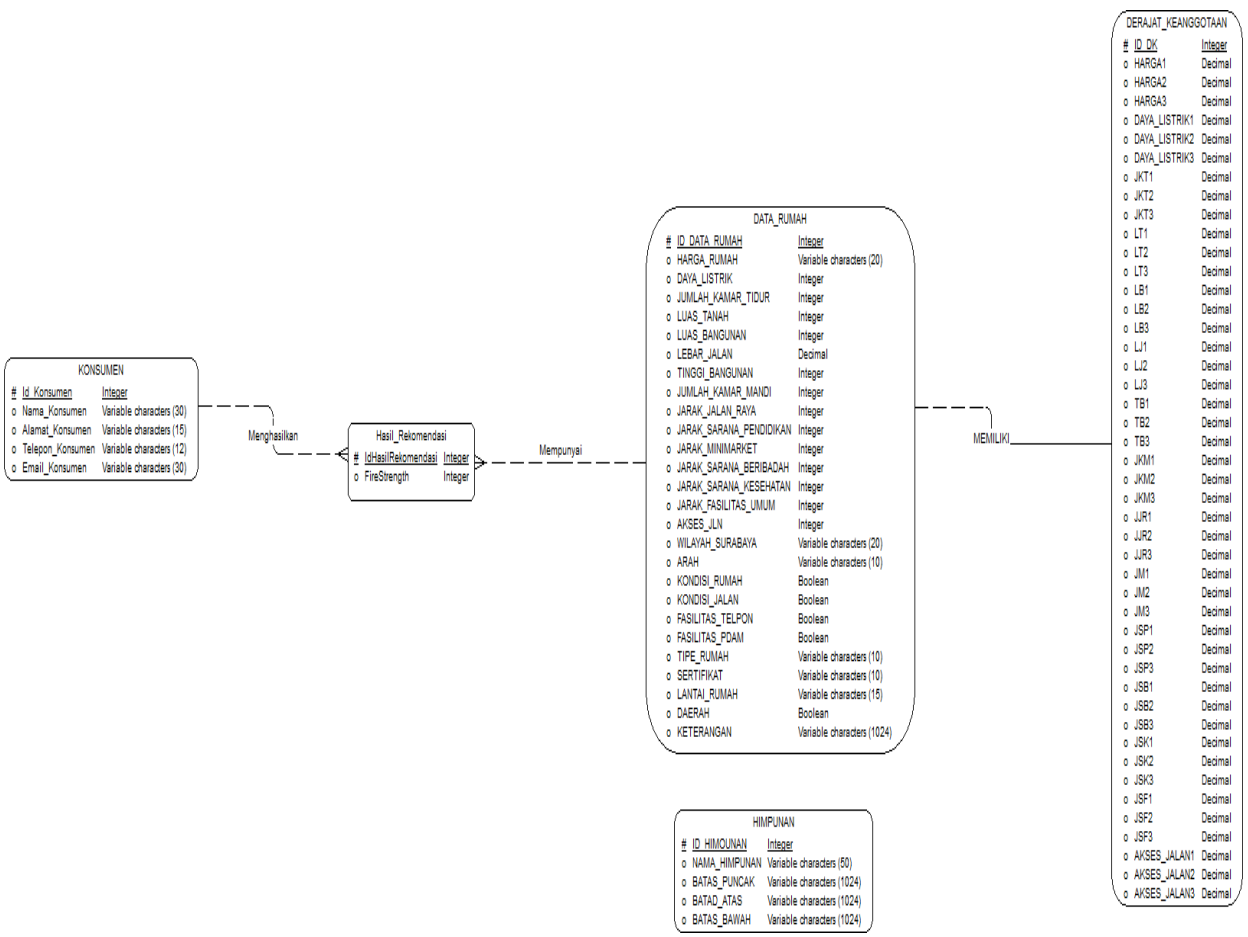

Gambar 11. Conceptual Data Model 


\section{User Interface}

Pada sub bab ini akan ditunjukkan tampilan antar muka dari aplikasi rekomendasi lokasi rumah yang nantinya akan berinteraksi dengan user.

\section{- Form Login}

Berikut tampilan form login untuk admin. Pada menu ini admin diharuskan login terhadap aplikasi, agar bisa menjalankan aplikasi.

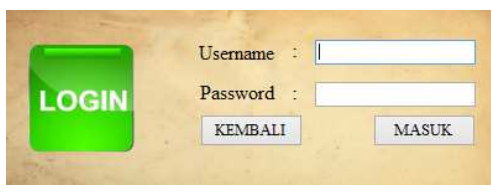

Gambar 12. Form Login

Berikut tampilan form login untuk konsumen. Pada menu ini konsumen diharuskan login terhadap aplikasi, agar bisa menjalankan aplikasi.

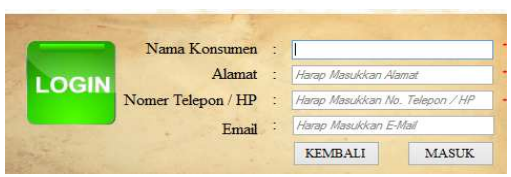

Gambar 13. Form Login Konsumen

\section{- Form Utama}

Berikut tampilan form utama pada aplikasi. Pada menu ini user dapat melihat semua pilihan menu yang terdapat dalam aplikasi. Pada menu utama ini terdapat MenuStrip yang menampung semua pilihan menu yang tersedia.

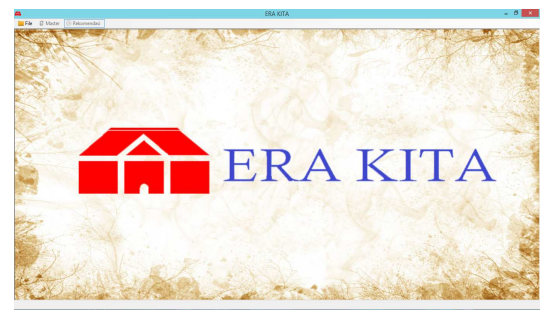

Gambar 14. Form Utama

\section{- Form Daftar Rumah}

Berikut tampilan form daftar rumah. Pada daftar rumah menampilkan data rumah yang berada di Surabaya pada sebuah datagridview. Pada data rumah juga terdapat menu file derajat keanggotaan yang berfungsi untuk menampilkan daftar derajat keanggotaan.

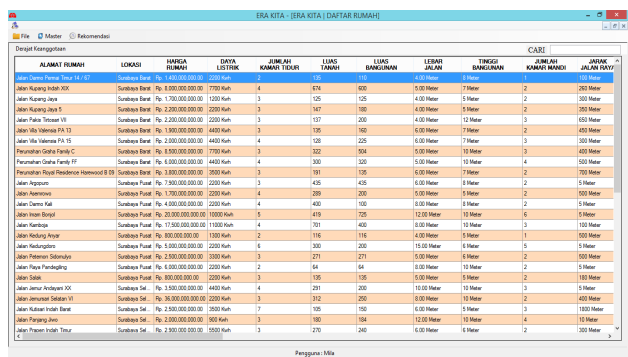

Gambar 15. Form Daftar Rumah

\section{- Form Tambah Data Rumah}

Berikut merupakan tampilan form tambah data rumah. Menu tambah data rumah hanya dapat diakses oleh admin dengan cara mengakses pada menu data rumah. Didalam sub menu tambah data rumah, user dapat melakukan penambahan data rumah baru.

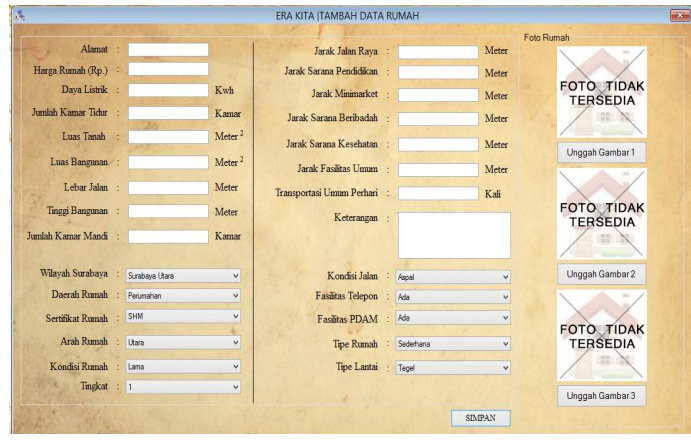

Gambar 16. Form Tambah Data Rumah

\section{- Form Rekomendasi}

Berikut tampilan form rekomendasi. Pada form rekomendasi hampir sama seperti form isi data rumah akan tetapi pada input textbox tidak harus menginputkan semuanya.

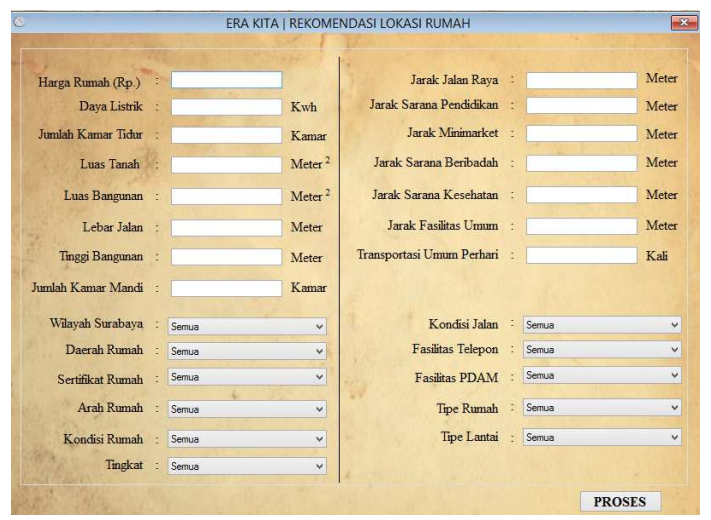

Gambar 17. Form Rekomendasi

\section{- Form Hasil Rekomendasi}

Berikut tampilan form hasil rekomendasi. Pada hasil rekomendasi ini menampilkan sesuai pilihan kriteria konsumen dan ada tanda button cetak yang berfungsi untuk konsumen ingin mencetak hasil rekomendasi.

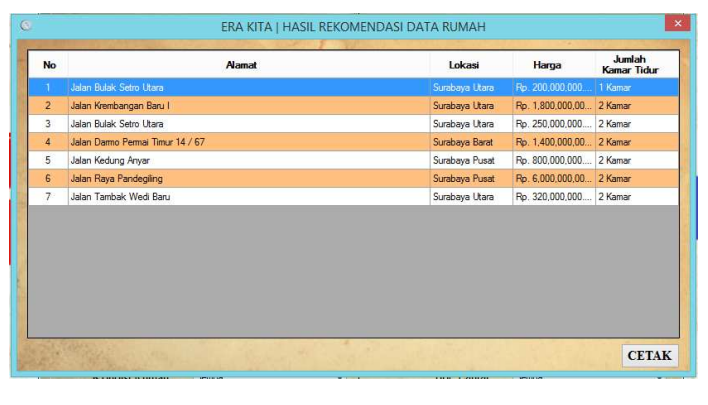

Gambar 18. Form Hasil Rekomendasi 


\section{E. Pengujian}

- Pengujian Aplikasi Sisi Admin

Dari proses uji coba yang telah dilakukan oleh 3 orang admin, dilanjutkan pengisian kuesioner sesuai dengan uji coba tersebut, maka didapatkan hasil uji coba aplikasi dari sisi admin seperti pada tabel berikut.

Tabel 1. Hasil Pengujian dari Sisi Admin

\begin{tabular}{|c|l|c|c|c|c|}
\hline \multirow{2}{*}{ No } & \multicolumn{2}{|c|}{ Pertanyaan } & \multicolumn{2}{|c|}{ Jawaban } & \multicolumn{2}{|c|}{ Presentase } \\
\cline { 3 - 5 } & Ya & Tidak & Ya & Tidak \\
\hline 1. & $\begin{array}{l}\text { Menurut anda, apakah saat mengisi data rumah } \\
\text { pada aplikasi ini mudah dimengerti? }\end{array}$ & 3 & 0 & $100 \%$ & $0 \%$ \\
\hline 2 & $\begin{array}{l}\text { Menurut anda, apakah semua detail dari masing- } \\
\text { masing rumah pada aplikasi ini sudah cukup } \\
\text { lengkap? }\end{array}$ & 3 & 0 & $100 \%$ & $0 \%$ \\
\hline 3. & $\begin{array}{l}\text { Menurut anda, apakah desain untuk mengisikan } \\
\text { data rumah dari aplikasi ini sudah cukup baik? }\end{array}$ & 3 & 0 & $100 \%$ & $0 \%$ \\
\hline 4. & $\begin{array}{l}\text { Menurut anda, apakahmenu-mermuyang adapada } \\
\text { aplikasi rekomendasi pemilihan lokasi rumah ini } \\
\text { sudah cukup dimengert? }\end{array}$ & 3 & 0 & $100 \%$ & $0 \%$ \\
\hline 5. & $\begin{array}{l}\text { Menurut anda, apakah proses unggah foto dari } \\
\text { masing-masing data rumahyang ada sudah cukup } \\
\text { baik? }\end{array}$ & 3 & 0 & $100 \%$ & $0 \%$ \\
\hline 6. & $\begin{array}{l}\text { Menurut anda, apakah data-data yang diinputkan } \\
\text { konsumen pada menu login konsumen sudah } \\
\text { dirasa cukup? }\end{array}$ & 3 & 0 & $100 \%$ & $0 \%$ \\
\hline 7. & $\begin{array}{l}\text { Menurut anda, apakah laporan yang dihasilkan } \\
\text { oleh aplikasi rekomendasi pemilihan lokasi } \\
\text { rumah ini sudah memenuhi kebutuhan? }\end{array}$ & 3 & 0 & $100 \%$ & $0 \%$ \\
\hline 8. & $\begin{array}{l}\text { Menurut anda, apakah desain pada menu input } \\
\text { kntenia oleh konsumen untuk mendapatkan } \\
\text { rekomendasi lokasi rumah dari aplikasi ini cukup } \\
\text { mudah dipahami? }\end{array}$ & 2 & 1 & $66,7 \%$ & $33,3 \%$ \\
\hline 9. & $\begin{array}{l}\text { Menurut anda, apakah desain keselunuhan guna } \\
\text { pemakaian aplikasirekomendasi pemilihan lokasi } \\
\text { rumah ini sudah cukup baik? }\end{array}$ & 3 & 0 & $100 \%$ & $0 \%$ \\
\hline
\end{tabular}

- Pengujian Aplikasi Sisi Konsumen

Dari proses uji coba yang telah dilakukan oleh 15 orang konsumen, dilanjutkan pengisian kuesioner sesuai dengan uji coba tersebut, maka didapatkan hasil uji coba aplikasi dari sisi konsumen seperti pada tabel berikut.

Tabel 2. Hasil Pengujian dari Sisi Konsumen

\begin{tabular}{|c|l|c|c|c|c|}
\hline \multirow{2}{*}{ No } & \multicolumn{1}{|c|}{ Pertanyaan } & \multicolumn{2}{|c|}{ Jawaban } & \multicolumn{2}{|c|}{ Presentase } \\
\cline { 3 - 6 } & Ya & Tidak & Ya & Tidak \\
\hline 1. & $\begin{array}{l}\text { Apakah input kriteria pada aplikasi ini mudah } \\
\text { dimengerti? }\end{array}$ & 15 & 0 & $100 \%$ & $0 \%$ \\
\hline 2. & $\begin{array}{l}\text { Apakah hasil rekomendasi yang diterima cukup } \\
\text { sesuai dengan kriteria yang anda cari? }\end{array}$ & 10 & 5 & $66,7 \%$ & $33,3 \%$ \\
\hline 3. & $\begin{array}{l}\text { Apakah hasil rekomendasi dapat membantu anda } \\
\text { untuk memilih rumah yang akan dibeli? }\end{array}$ & 10 & 5 & $66,7 \%$ & $33,3 \%$ \\
\hline 4. & $\begin{array}{l}\text { Menurut anda, apakah informasi tentang detail } \\
\text { dari setiap rumah yang dijual pada aplikasi ini } \\
\text { sudah cukup lengkap? }\end{array}$ & 15 & 0 & $93 \%$ & $0 \%$ \\
\hline 5. & $\begin{array}{l}\text { Apakah laporan yang dihasilkan oleh aplikasi } \\
\text { rekomendasi pemilihan lokasi rumah ini sudah } \\
\text { memenuhi kebutuhan anda? }\end{array}$ & 15 & 0 & $100 \%$ & $0 \%$ \\
\hline 6. & $\begin{array}{l}\text { Menurut anda, apakah desain pada menu input } \\
\text { kriteria untuk menghasilkan rekomendasi lokasi } \\
\text { rumah dari aplikasi ini cukup mudah dipahami? }\end{array}$ & 15 & 0 & $100 \%$ & $0 \%$ \\
\hline 7. & $\begin{array}{l}\text { Menurut anda, apakah desain pada menu hasil } \\
\text { rekomendasi dari aplikasi rekomendasi pemilihan } \\
\text { lokasi rumah ini sudah cukup baik? }\end{array}$ & 15 & 0 & $100 \%$ & $0 \%$ \\
\hline 8. & $\begin{array}{l}\text { Menurut anda, apakah desain keseluruhan dari } \\
\text { aplikasi rekomendasi pemilihan lokasi rumah ini } \\
\text { sudah cukup baik? }\end{array}$ & 15 & 0 & $100 \%$ & $0 \%$ \\
\hline
\end{tabular}

\section{KESIMPULAN DAN SARAN}

A. Kesimpulan

Dalam pembuatan aplikasi rekomendasi pemilihan lokasi rumah dengan menggunakan algoritma fuzzy database metode tahani ini penulis dapat mengambil kesimpulan yaitu kuesioner yang disebarkan kepada responden cukup membantu dalam proses penentuan batas-batas himpunan fuzzy. Setelah melalui tahapan uji coba, aplikasi rekomendasi pemilihan lokasi rumah ini terbukti dapat menghasilkan daftar rekomendasi pemilihan lokasi rumah yang mendekati dengan kriteria yang diinginkan oleh konsumen.

B. Saran

Penulis menyadari bahwa aplikasi ini masih jauh dari kesempurnaan. Oleh karena itu penulis memberikan saransaran yang berguna dalam pengembangan sistem lebih lanjut yaitu:

- Aplikasi rekomendasi lokasi rumah ini tidak menampilkan informasi sales. Konsumen yang ingin mendapat informasi rumah dan transaksi lebih lanjut, sebaiknya output dari aplikasi ini dilengkapi dengan informasi sales dari rumah tersebut.

- Aplikasi ini bisa dikembangkan menjadi aplikasi berbasis web atau mobile.

- Aplikasi ini dapat terus dikembangkan lebih lanjut baik dalam hal penentuan variabel, dan nilai batasan himpunan fuzzy.

\section{REFERENSI}

[1] Kusumadewi, Sri dan Hartati, Sri. (2006), Neuro-Fuzzy: Integrasi Sistem Fuzzy dan Jaringan Syaraf, Graha Ilmu, Yogyakarta.

[2] Kusumadewi, Sri dan Purnomo, Hari. (2010), Aplikasi Logika Fuzzy untuk Pendukung Keputusan, Graha Ilmu, Yogyakarta.

[3] Connolly, Thomas and Carolyn Begg (2005). Database System: A Practical Approach to Design, Implementation, and Management, 4th ed. Addison Wesley.

[4] Davis William S. (1998). Business System Analysis \& Design. Thomson Publ.

[5] Jeffry, H. A. (1999). Modern System Analysis \& Design. AddisonWesley : California.

[6] Putri Martasari Rindriana (2012). Kelebihan dan Kekurangan dari Perangkat Lunak yang menangani semua pengaksesan Database. Seamolec.

[7] Suhendar A. (2002). Visual Modelling Menggunakan UML dan Rational Rose, Informatika Bandung, Bandung.

[8] Microsoft Visual Studio History. Tersedia di : $<\mathrm{http}: / / \mathrm{www}$.devarticles.com/c/b/VB.Net/>

[9] Teori Flowchart. Tersedia di: < http://www.academia.edu/7522478/System_Flowchart> 